\title{
Ensino de técnicas de análises de minerais com ênfase na interpretação de dados: teoria e prática na formação do geólogo
}

Carlos Jorge da Cunha ${ }^{1}$ cjdcunha@quimica.ufpr.br Orliney Maciel Guimarães ${ }^{1}$

Márcio Peres de Araújo ${ }^{1}$

Eleonora Maria Gouvêa Vasconcellos ${ }^{2}$

Joaniel Munhoz Martins ${ }^{2}$

José Manoel dos Reis Neto ${ }^{2}$

Fernanda Machado Martins ${ }^{1}$

${ }^{1}$ Depto. Química da Universidade Federal do Paraná.

${ }^{2}$ Depto. Geologia da Universidade Federal do Paraná
*Este documento deve ser referido como segue:

Cunha J.C., Guimarães 0 . M., Araújo M. P., Vasconcellos E.M.G., Martins J. M., Reis-Neto J. M., Martins F. M., 2008. Ensino de técnicas de análises de minerais com ênfase na interpretação de dados: teoria e prática na formação do geólogo Terræ Didatica, 4(1):14-27 $<$ http://www.ige.unicamp.br/ terraedidatica/ $>$

\begin{abstract}
Teaching of mineral analysis techniques with emphasis on data interpretation: theory and practice for training a geologist. An educational activity devised as part of the Experimental Inorganic Chemistry course aims at the compliance with the National Curriculum Directives for Geology and Engineering Geology undergraduate courses. The activity has allowed to engage theory and practice by means of data interpretation of analytical instrumental characterization of the elemental, structural and mineralogical composition of minerals and rocks. Twelve selected samples of minerals were analysed by $X$-ray fluorescence, powder X-ray diffraction, scanning electron EDS probe microscopy and optical microscopy (petrography). The non-interpreted results were made available in a homepage and students were requested to interpret the data to identify the samples. Teachers have evaluated the activity to be suitable for a Descriptive Mineralogy course; it also helps meeting the needs of formation of a geologist, which currently requires entangling knowledge and action as to interpret reality, to understand processes, to identify problems and to generate solutions.
\end{abstract}

KEYWORDS Analysis of minerals and rocks, educational material, geologist's formation, competence, theory and practice.

RESUMO Atividade didática inicialmente desenvolvida na disciplina Química Inorgânica Experimental, ministrada aos alunos do Curso de Geologia da UFPR objetivou atender às Diretrizes Curriculares Nacionais para formação do geólogo e do engenheiro geólogo. A atividade buscou articular teoria e prática por meio da interpretação de dados de análise instrumental de caracterização elementar, estrutural e mineralógica de minerais e rochas. Para desenvolvimento, 12 amostras de minerais foram selecionadas e analisadas por fluorescência de raios $X$, difração de raios $X$ de pó, microscopia eletrônica de varredura com sonda EDS e microscopia óptica (Petrografia). Documento com os resultados não-interpretados foi disponibilizado aos alunos em uma homepage e foi solicitado que os alunos identificassem as amostras por meio da interpretação dos dados. A avaliação dos professores ao final do trabalho foi de que a proposta apresentada é adequada para a disciplina de Mineralogia Descritiva e ajuda a atender às demandas exigidas para formação do geólogo, que hoje passam pelo pensar, pelo ler a realidade, compreender os processos, identificar problemas e gerar soluções, exigindo a articulação entre o fazer e o conhecer.

PALAVRAS CHAVE Análise de minerais e rochas, material didático, formação do geólogo, competências, articulação entre teoria e prática. 


\section{Introdução}

As modificações ocorridas no mundo do trabalho, referentes a muitas questões atualmente colocadas no panorama mundial, como a globalização, a produção flexível e as novas demandas do mercado de trabalho, exigem adequação do perfil profissional, o que deve impactar diretamente a formação profissional.

Estas exigências do mundo do trabalho fizeram com que o MEC estabelecesse mudanças nos cursos de graduação de todo o país, por meio de diretrizes curriculares que deveriam ser discutidas por uma comissão de especialistas para cada área específica. No caso dos cursos de Geologia a comissão de especialistas foi incumbida de elaborar a proposta inicial para discussão, sem no entanto ter sido atingido um consenso. O MEC não aprovou plenamente a proposta. Em paralelo, os coordenadores de cursos de graduação de Geologia e Engenharia Geológica de todo o país realizaram dois seminários nacionais, que culminaram na criação do Fórum Nacional de Cursos de Geologia, entidade voltada para fomentar e conduzir essas e outras discussões e que adquiriu status permanente. Diversos encontros foram realizados para propiciar debates sobre a formação do geólogo (Carneiro et al. 2002, 2003, 2004; Assis et al. 2005), tendo sido apresentada e publicada uma versão de Diretrizes Curriculares Nacionais (DCNs) (Nummer et al. 2005) elaborada pelo Fórum.

Nessas discussões verificou-se a preocupação em formar profissionais de nível superior competentes, com conhecimento e iniciativa, e que possam ser absorvidos pelo mercado de trabalho.

As Diretrizes Curriculares Nacionais (Nummer et al. 2005) para cursos de Geologia e Engenharia Geológica descrevem o seguinte perfil dos formandos:

“...com condição de trabalhar em qualquer área de atuação das Ciências Geológicas, que tenha interesse e capacidade para o trabalho de campo; visão abrangente das Geociências e de suas interações com ciências correlatas; pleno dominio da linguagem técnica geológica aliada à capacidade de adequação desta linguagem à comunicaşão com outros profissionais e com a sociedade; conhecimento de ciências exatas que permita abordagens quantitativas das informações geológicas; familiaridade com métodos e técnicas de informática, especialmente no tocante ao geoprocessamento".

A formação generalista descrita nas DCNs deverá ser construída a partir de "um treinamento prático intensivo" e conteúdos complementares que permitam ao egresso: "...ter atitude ética, autônoma, crítica, criativa, empreendedora e atuação propositiva, na busca de soluções de questões de interesse da sociedade", neste caso são sugeridos conteúdos de Ciências Humanas, tais como: Economia, Filosofia da Ciência, Gestão, Administração e Comunicação.

As competências e habilidades do Geólogo previstas nas DCNs, dentre outras, referem-se a planejar, executar, gerenciar, avaliar e fiscalizar projetos, serviços e ou pesquisas científicas básicas ou aplicadas que visem ao conhecimento e à utilização racional dos recursos naturais e do ambiente, o aproveitamento tecnológico dos recursos minerais e energéticos sob o enfoque de mínimo impacto ambiental, novas alternativas de explotação, conservação e gerenciamento de recursos hídricos; aplicar métodos e técnicas direcionadas a gestão ambiental e atuar em áreas de interface, como a Tecnologia Mineral, Ciências do Ambiente e Ciências do Solo. Para atender estas habilidades e competências são propostas disciplinas de conteúdo básico (Matemática, Estatística, Física, Computação, Química, Biologia e Geociências), conteúdo para formação geológica específica, conteúdos temáticos, atividades de campo, conteúdo complementar (optativo) e estágio supervisionado (optativo).

Segundo Kuenzer (2003), com o rápido avanço da Ciência e sua incorporação ao setor produtivo (reestruturação produtiva), o mundo mudou e mudou o conceito de competência, sobre o que é ser competente no mundo do trabalho. Se antes a competência visava tão somente à produtividade advinda da repetição acertada de procedimentos, o paradigma taylorista/fordista (Antunes 2001), hoje passa pelo pensar, pelo ler a realidade, compreender os processos, identificar problemas e gerar soluções, exigindo a articulação entre o fazer e o conhecer. É esta compreensão que vai permitir que o profissional seja competente e seja flexível em uma realidade na qual o próprio conhecimento torna-se ultrapassado com velocidade muito rápida.

O conceito de competência atual pode e deve servir como ponte entre as Universidades e o mercado de trabalho na medida em que este necessita de profissionais competentes que saibam lidar com situações novas, tomando decisões adequadas por intermédio da utilização do conhecimento científico e das experiências passadas. 
Apesar do discurso de que toda e qualquer educação sempre será educação para o trabalho, é preciso distinguir a que visa aos interesses do trabalhador, daquela que visa aos interesses do capital.

Do ponto de vista do capital, para aumentar a competitividade na busca pelo emprego, o profissional deve ampliar suas possibilidades de desempenho, complementando sua formação acadêmica específica, por exemplo por meio de cursos de língua estrangeira, gerência, recursos humanos e relações interpessoais, para se tornar um profissional multidisciplinar e capaz de corresponder às necessidades da empresa não só na área de Geologia. Neste caso o enfoque é a qualificação individual.

Segundo nosso ponto de vista, a inserção dos novos profissionais decorre de uma expansão do mercado de trabalho em função do dinamismo econômico do país. A empregabilidade não constitui responsabilidade direta da universidade e nem, necessariamente, a competência profissional individual a garantia de emprego. Tal compreensão não significa recusar o desafio de superar as dificuldades para criar profissionais com uma formação sólida e ampla, que favoreça o trabalhador.

As características consideradas hoje fundamentais em quaisquer setores de atividade, sejam eles acadêmico ou industrial, como: visão crítica, capacidade de tomar decisões e, principalmente, que aprendam a aprender inseridos na realidade histórico-social, política e econômica do país, evidenciam a necessidade de uma educação de qualidade, não só na graduação, mas desde o ensino fundamental e médio.

Mais do que nunca, o ensino superior deverá superar a concepção conteudista que o tem caracterizado, em face de sua versão predominantemente propedêutica, para promover mediações significativas entre os jovens e o conhecimento científico, articulando saberes tácitos, experiências e atitudes; do contrário, deixará de ser útil tanto para o capital quanto para o trabalhador.

Consideramos que a atividade profissional se concretiza como práxis humana (Marx 1999), a categoria práxis é central para Marx, visto que a partir dela tem sentido a atividade do homem, sua história e o seu conhecimento. Esta forma de conceber o trabalho significa reconhecê-lo como atividade ao mesmo tempo teórica e prática, intelectual e instrumental, reflexiva e ativa. No trabalho, articulam-se a teoria e a prática como momentos inseparáveis do processo de construção do conhecimento e da transformação da realidade (Kuenzer 2001).

Segundo a lógica da cisão entre a teoria e a prática, a concepção de currículo na Universidade tem por base o pressuposto de que há um tempo de aprender a pensar e um tempo de aprender a fazer. Segundo Kuenzer (2001), muitas vezes "o estágio curricular e extra-curricular tem sido a única janela, por onde saem os ares da teoria para encontrar os bafejos da prática, na tentativa, quase sempre frustrada, de buscar a reunificação da dialética rompida".

Assim o ensino na Universidade se faz por fragmentos da teoria, supostamente autônomos entre si distribuídos em conteúdos de caráter geral e os profissionalizantes propriamente ditos. Após passar por todos eles, virá finalmente à hora da prática, momento em que haverá "reunificação" do saber dividido: a atuação profissional.

O curso de Geologia da UFPR não passou por uma reforma curricular para atender às novas demandas do mercado de trabalho e se adequar às DCNs. Desta maneira os professores da disciplina Química Inorgânica e Experimental do curso de Geologia, cientes de que o saber fazer é importante em qualquer profissão, mas o saber pensar é fundamental para tomada de decisão, buscaram, por meio da discussão com os professores das disciplinas de Mineralogia Geral, Mineralogia Descritiva e Geoquímica, uma forma de introduzir uma atividade, nesta disciplina de química, que venha articular o conhecimento teórico e a prática na formação inicial dos estudantes de Geologia. A química faz parte do núcleo básico do atual currículo do curso de Geologia e a realização desta atividade permitirá aos estudantes refletirem sobre a importância dos conteúdos das disciplinas básicas na graduação e construir habilidades específicas no seu campo de atuação. Este exercício e a criação de uma disciplina de química aplicada à mineralogia, se considerado positivo para desenvolver habilidades e competências para a formação em Geologia, será encaminhado como proposta ao colegiado do curso de Geologia para incorporação oficial ao currículo.

\section{Análise de minerais e rochas: saber fazer ou saber pensar?}

Há mais de trinta anos atrás as análises químicas de minerais e rochas eram feitas por via úmida com abertura de amostra em ácidos, titulações, 
gravimetria e outros procedimentos qualitativos de laboratório (Afonso et al. 2004), tais como: fusão em pérola de bórax, testes de chama, aquecimento em carvão, etc. Estas atividades eram exclusivamente desenvolvidas por químicos e os resultados, apesar de obtidos a partir de um trabalho árduo e demorado, eram simples listagens de teores ou resultados qualitativos.

Com o desenvolvimento e a popularização das técnicas analíticas instrumentais (Skoog 1998), tais como difração de raios X(DRX), análise elementar por fluorescência de raios X (FRX) e microscopia eletrônica de varredura (MEV), o trabalho para obtenção de dados foi grandemente reduzido mas a complexidade teórica da interpretação cresceu muito. Estas técnicas são instrumentos poderosos para se identificar minerais e rochas (Gomes 1984) e definir suas origens. No passado os geólogos e mineralogistas dispunham apenas da microscopia óptica e resultados de análises químicas, mas atualmente contam também com DRX, MEV e microssonda eletrônica que podem fornecer análises químicas de pontos selecionados da amostra.

O ensino de técnicas analíticas modernas foi então sendo introduzido a princípio na disciplina de Química Inorgânica Experimental no curso de Geologia da UFPR, ministrada concomitantemente com a disciplina de Mineralogia Descritiva, semestre após semestre, por meio de um trabalho realizado em equipe e a partir dos resultados obtidos nesta experiência didática, parte dele tem sido desenvolvido na disciplina de Mineralogia Descritiva.

Em nosso ponto de vista, o ensino de técnicas analíticas para análise de minerais e rochas para Geologia vai além do domínio da técnica, do saber manipular as amostras e o próprio equipamento, pois na sua atuação profissional o geólogo poderá não dispor desta ferramenta o que o fará a recorrer a serviço de terceiros e geralmente, estes equipamentos são operados por técnicos treinados para este fim. Já o saber interpretar os dados para, a partir deles, tomar decisões é uma experiência que pode e deve ser disponibilizada aos geólogos durante a sua formação inicial. Articular este saber teórico quando se estuda as propriedades dos elementos químicos e como eles se apresentam nos minerais e rochas fornecem significado ao aprendizado e evitamos a cisão entre teoria e prática, por meio da qual há um tempo de aprender a pensar e um tempo de aprender a fazer.
Apesar das técnicas analíticas instrumentais terem se tornado muito importantes em Geologia, a literatura ainda é carente de livros especializados no assunto. O livro de Klein \& Hurlbut (Klein \& Hurlbut 1999) tem apenas um capítulo sobre as técnicas analíticas, o qual é apenas informativo e ausente de exemplos. A abordagem de Gomes (Gomes 1984), a melhor disponível em língua portuguesa, está desatualizada. Apesar de existirem excelentes textos sobre análises instrumentais (Skoog 1998, Harris 2002) nenhum deles está contextualizado para a Geologia. O texto de Gill (Gill 1989), sobre os fundamentos de Química para Geologia, um dos poucos livros que trata do assunto, não tem enfoque analítico. Há alguns livros direcionados para Geologia, especializados em uma técnica, como por exemplo, o livro intitulado Electron Microprobe Analysis and Scanning Electron Microscopy in Geology (Reed 2005).

Para suprir a deficiência de textos atualizados, em língua portuguesa, sobre as técnicas analíticas aplicadas à Geologia, o uso de resultados publicados em artigos tem se revelado útil, mas estes trazem o viés da interpretação dos dados.

Os professores de química e de mineralogia sentiram a necessidade de desafiar os alunos de suas disciplinas com dados ainda não interpretados. Uma alternativa seria fornecer amostras reais aos alunos e solicitar a eles que coletassem os dados analíticos. Infelizmente esta abordagem em nosso caso é inviável, tendo em vista que a infraestrutura analítica da Universidade tem priorizado as atividades de pesquisa e sofre inconstâncias, tais como equipamentos com defeito ou em manutenção preventiva.

Muitos estudantes pensam que saber usar um equipamento e dele retirarem gráficos e tabelas é um grande aprendizado para a formação profissional (saber fazer). No entanto, ao se depararem com os gráficos e tabelas e tentarem interpretar os resultados, chegam à conclusão de que interpretar é bem mais difícil do que usar o equipamento (saber pensar). Partindo deste ponto de vista os autores acreditam que a ênfase do ensino das técnicas analíticas deve ser na interpretação e não no uso dos equipamentos que vem se tornando cada vez mais fácil com o continuado avanço da automação e dos softwares de operação. O presente trabalho é uma proposta de atendimento à necessidade educacional exposta acima contornando as limitações de infraestrutura presente na universidade. 
A atividade didática aqui apresentada foi desenvolvida na disciplina de Química Inorgânica Experimental, ministrada pelo Departamento de Química, aos alunos do curso de Geologia da UFPR com a finalidade principal de possibilitar aos alunos articularem a fundamentação teórica relacionadas às técnicas instrumentais utilizadas para caracterizar a composição química, estrutural e mineralógica de minerais e rochas com a prática de interpretar dados provenientes de amostras reais. Para o desenvolvimento desta atividade foi produzido um material didático composto de um conjunto de dados coletados a partir do segundo semestre de 2004 e que também são utilizados na disciplina Mineralogia Descritiva, ministrada pelo Departamento de Geologia. As técnicas usadas até o momento e que geraram os dados foram: microscopia ótica em microscópio petrográfico com luz polarizada, microscopia eletrônica de varredura (MEV) com microssonda EDS (Energy Dispersive Spectroscopy), difração de raios $\mathrm{X}$ de pó (DRX) e análise elementar por fluorescência de raios $\mathrm{X}$ (FRX).

\section{Metodologia da abordagem educacional}

A metodologia utilizada para a realização da atividade didática proposta consistiu em disponibilizar aos alunos dados analíticos reais coletados em amostras de minerais e rochas da forma como foram obtidos diretamente dos equipamentos, bem como a metodologia de análise utilizada e as condições experimentais utilizadas para sua obtenção, e demandar interpretações e respostas aos questionamentos propostos pelos professores. Os dados estão disponibilizados em um documento, que pode ser obtido de um site institucional da internet (http://www.geologia.ufpr.br/graduacao/ gradtextos.php). A metodologia de análise é explicitada no texto que acompanha o documento. $\mathrm{O}$ contexto geológico das amostras não é fornecido em detalhes para que a interpretação dos resultados não possa ser descoberta em uma pesquisa bibliográfica. No entanto, a realização de pesquisa bibliográfica, relevante à solução de problemas, é solicitada.

Desta forma, o aluno, além dos dados obtidos da análise realizada, terá que recorrer à literatura para embasar suas interpretações e identificar a amostra de mineral ou rocha que está sendo proposta.

O documento poderá ser alterado sempre que adaptações sejam feitas incluindo novas amostras ou resultados de novas técnicas sobre amostras já existentes.

No texto a seguir, chamado "documento fornecido aos alunos", apresentamos a parte introdutória, com a finalidade de ilustrar. Fornecemos um exemplo de dados obtidos para a amostra de Piroxênio.

A atividade descrita foi aplicada no segundo semestre de 2006 e fez parte da avaliação da disciplina "Química Inorgânica e Experimental", ministrada pelo Departamento de Química ao curso de Geologia da UFPR.

Cada documento de análise de um mineral foi atribuído a uma equipe de dois alunos. A cada equipe coube analisar os dados, entregar um trabalho escrito com interpretações e respostas às questões postuladas no documento e realizar uma apresentação oral para a turma no final do semestre.

\section{Documento fornecido aos alunos}

\section{Introdução}

O documento a seguir possui dados analíticos coletados em diversas amostras de minerais. A seção de metodologia explicita os detalhes da coleta dos dados. Os resultados para cada amostra são em seguida apresentados, em uma seção específi$\mathrm{ca}$, tais como foram obtidos dos equipamentos, $\mathrm{e}$ não estão interpretados. O professor irá atribuir uma ou mais amostras para sua equipe. No fim de cada seção há questões para você responder usando os dados disponíveis e/ou pesquisa bibliográfica e internet. Dentre os dados coletados pode haver informações redundantes ou desnecessárias para a resposta às questões propostas, você deve decidir quais dados devem usar. O objetivo do trabalho é simular a real atividade de caracterização analítica de minerais e rochas com ênfase na interpretação dos resultados e não na obtenção dos mesmos.

\section{Metodologia de Coleta de Dados Analíticos}

A tabela 1 lista doze amostras de minerais selecionadas e suas respectivas procedências. Na figura 1 podem ser vistas as amostras em bloco que estão 
Tabela 1 - Amostras de minerais e rochas, sua respectiva procedência e tipo de aplicativo de calibração usada na análise elementar de FRX realizada

\begin{tabular}{c|c|c|c|c}
\hline seção & rocha/mineral & estado físico & procedência & $\begin{array}{c}\text { aplicativo de } \\
\text { calibração FRX }\end{array}$ \\
\hline 1 & Barita & bloco & Minas Gerais & semi-q \\
\hline 2 & Calcita & bloco & Paraná & quantitativo \\
\hline 3 & Feldspato & bloco & Paraná & semi-q \\
\hline 4 & Galena & bloco & Adrianópolis - Paraná & semi-q \\
\hline 5 & Ilmenita & bloco & Minas Gerais & semi-q \\
\hline 6 & Calcopirita & bloco & Carajás - Pará & quanti-q \\
\hline 7 & Piroxênio & bloco & Minas Gerais & semi-q \\
\hline 8 & Quartzo & bloco & Rio Grande do Sul & semi-q \\
\hline 9 & Turmalina & bloco & Minas Gerais & semi-q \\
\hline 10 & Zeólita & bloco & Londrina - Paraná & semi-q \\
\hline 11 & Talco & pó & Itaiacoca - Paraná & \\
\hline 12 & Argila & pó & Rio Branco do Sul - Paraná & \\
\hline
\end{tabular}

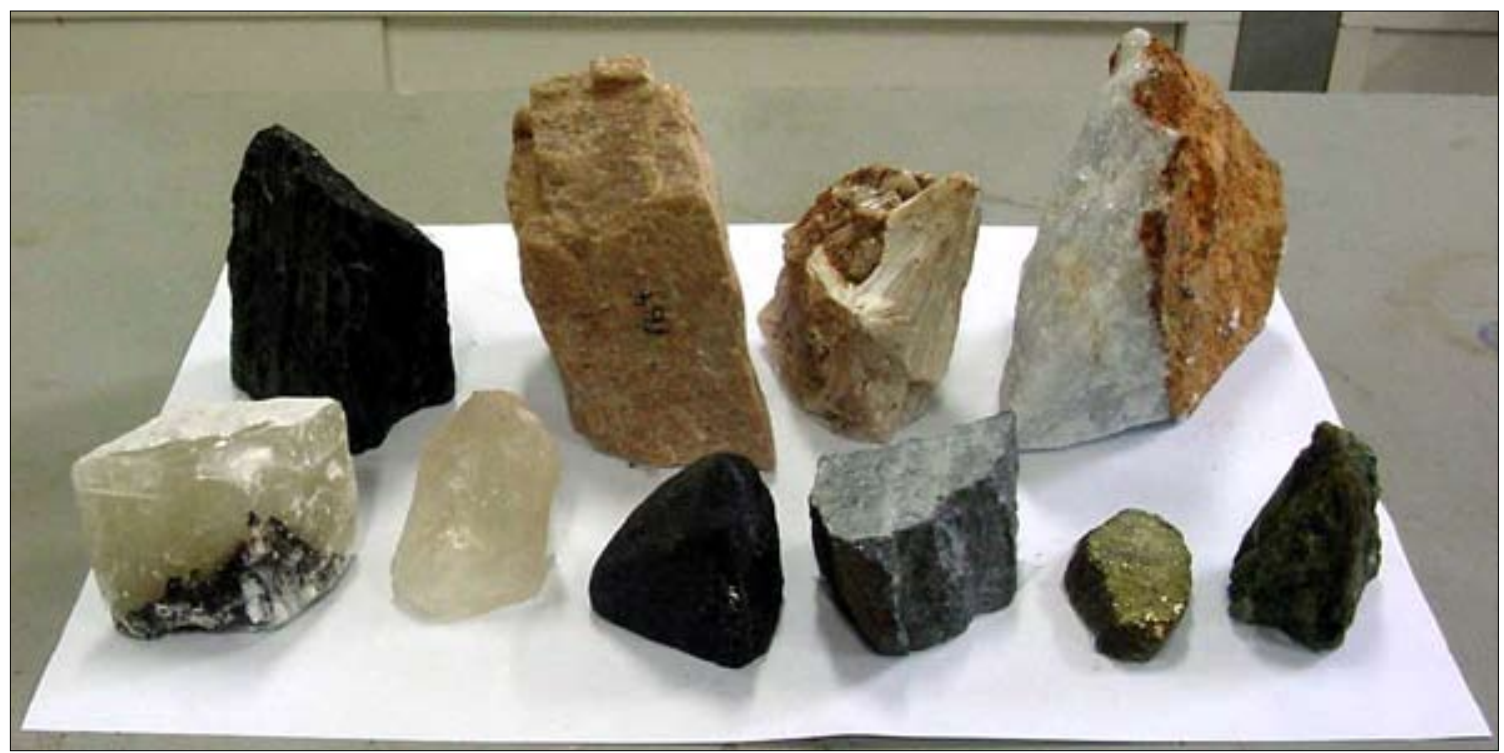

Figura 1 - Amostras usadas no presente trabalho. De cada amostra foi cortada uma parte para confecção de lâmina petrográfica e pulverização. Estas amostras ficam disponíveis no laboratório para os alunos analisarem durante a realização do trabalho. Em cima, da esquerda para a direita : turmalina, feldspato, zeólita, barita. Em baixo, da esquerda para a direita : calcita, quartzo, ilmenita, galena, calcopirita, piroxênio. A folha de papel tem tamanho A4

disponíveis no laboratório para inspeção.

\section{Microscopia Óptica (Petrografia) e Microscopia Eletrônica de Varredura}

Foi confeccionada uma lâmina petrográfica de cada amostra, cortada em serra diamantada e colada com araldite sobre uma lâmina de vidro de $2 \times 2 \mathrm{~cm}$. A lâmina foi polida até a espessura aproximada de $0,03 \mathrm{~mm}$ e foi usada para a identificação dos minerais em um microscópio de luz polarizada, modelo Olympus SZ-CTV, e imagens micrográficas foram capturadas com o microscópio Olympus BX60, com o software Image-Pro Plus, disponíveis no Laboratório de Mineralogia e Petrologia (LAMIN) do Departamento de Geologia da UFPR. A mesma lâmina foi usada para registrar as imagens BSE (elétrons retro espalhados), os espectros EDS pontuais e os mapas bidimensionais de composição elementar, no microscópio eletrônico de varredura, modelo JEOL JSM-6360, Low Vaccum, com probe EDS thermonoran, do Centro de 
Microscopia Eletrônica CME do Setor de Ciências Biológicas da UFPR.

\section{Fluorescência de Raios X (FRX) e Difração de Raios $X(D R X)$}

Uma parte de cada amostra de rocha foi cortada, britada e pulverizada. As amostras de Argila e Talco foram apenas secas $\left(80^{\circ} \mathrm{C}, 24 \mathrm{~h}\right)$ e pulverizadas. Para as amostras de Calcita, Feldspato e Quartzo, parte do pó foi usado para confeccionar uma pastilha em pérola de tetraborato de lítio. Para as amostras de Galena, Ilmenita, Calcopirita, Barita, Turmalina, Piroxênio, Zeólita, Talco e Argila parte do pó foi prensado em forma de pastilha. Cada pastilha (pérola ou pó prensado) foi usada para se registrar os espectros de FRX, dos quais se extraiu a composição química por manipulação dos dados com a linha de calibração mais apropriada. A linha de calibração, semi-quantitativa (semi-q), ou quantitativa, usada para cada amostra, pode ser vista na tabela 1. O equipamento usado foi o Espectrômetro de Raios X Phillips PW 2400 do LAMIR.

Parte do pó, de cada amostra, foi usada para a determinação da perda ao fogo. Antes da determinação da perda ao fogo a amostra em pó é seca a $100^{\circ} \mathrm{C}$ por 8 horas. No experimento de perda ao fogo, cerca de 1 grama de amostra seca é pesada, com exatidão (M1 = massa do cadinho mais amostra), dentro de um cadinho de porcelana $(\mathrm{Mc}=$ massa do cadinho vazio) e é aquecida a $1000^{\circ} \mathrm{C}$ por três horas. Após resfriado à temperatura ambiente o cadinho com a amostra calcinada é pesado (M2 = massa do cadinho mais amostra calcinada). A perda ao fogo, percentual, é calculada a partir da relação $100 \times[(M 1-M 2) /($ Mc-M1)].

Parte do pó, de cada amostra seca, foi usada para se obter um difratograma, em modo $\theta / 2 \theta$, entre 10 e $80^{\circ}$ no Difratômetro de Raios X Shimadzu LabXXRD 6000, do Departamento de Química da UFPR, com radiação Cu-K $\alpha(\lambda=1,5418 \AA$ ) .

\section{Resultados}

Os resultados das análises químicas elementares por FRX, os difratogramas de raios X, as imagens de MEV-EDS, os espectros de EDS e as imagens de microscopia ótica, são apresentados na seção relativa a cada amostra. Os difratogramas estão disponíveis em planilhas eletrônicas de cálculo no computador do laboratório de ensino os quais podem ser manipulados ou copiados em formato eletrônico.
Um exemplo:

\section{Resultados para a amostra Piroxênio}

\section{FRX}

A tabela A-1 traz os resultados da análise química elementar feita por fluorescência de raios X.

\begin{tabular}{l} 
Tabela A1- Amostra piroxênio por FRX \\
\cline { 2 - 2 } \\
$\qquad$\begin{tabular}{c|c}
\hline $\mathrm{Al}_{2} \mathrm{O}_{3}$ & Piroxênio \\
\hline $\mathrm{CaO}$ & 0,73 \\
\hline $\mathrm{Cr}$ & 03,80 \\
\hline $\mathrm{Fe}_{2} \mathrm{O}_{3}$ & 5,72 \\
\hline $\mathrm{MgO}$ & 11,41 \\
\hline $\mathrm{MnO}$ & 0,19 \\
\hline $\mathrm{Na}$ & $<<$ \\
\hline $\mathrm{Ni}$ & $<<$ \\
\hline $\mathrm{P}$ & $<<$ \\
\hline $\mathrm{S}$ & $<<$ \\
\hline $\mathrm{SiO}$ & 55,81 \\
\hline $\mathrm{Sr}$ & $<<$ \\
\hline $\mathrm{Zn}$ & $<<$ \\
\hline $\mathrm{P.F}$ & 2,15 \\
\hline
\end{tabular}
\end{tabular}

\section{MEV com EDS}

A inspeção da amostra de Piroxênio, com imagens BSE, revelou a possível presença de mais de uma fase devido às diferentes texturas observadas. Uma imagem BSE representativa pode ser vista na figura A-1.

Na região em foco na figura A-2 foram selecionados quatro pontos, indicados sobre a imagem, para a coleta dos espectros de EDS mostrados na figura A-3 e tabela A-2.

Tendo em vista que os quatro espectros revelaram composições químicas muito semelhantes não foi feito mapeamento químico.

\section{DRX}

A figura A-4 tem o difratograma de raios X de pó da amostra de Piroxênio.

\section{Microscopia óptica}

A partir da lâmina delgada foram obtidas fotomicrografias da amostra analisada, com polarizadores paralelos e cruzados, conforme figuras A-5a e A-5b, respectivamente. 


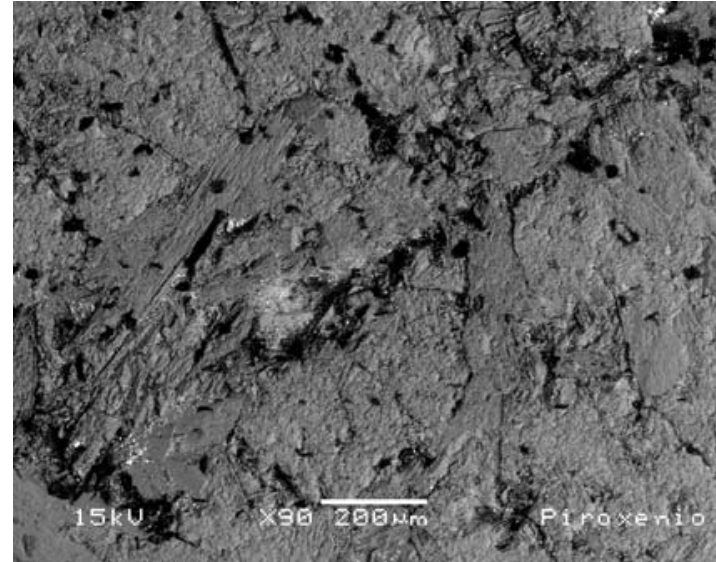

Figura A-1 - Imagem BSE obtida na amostra de Piroxênio

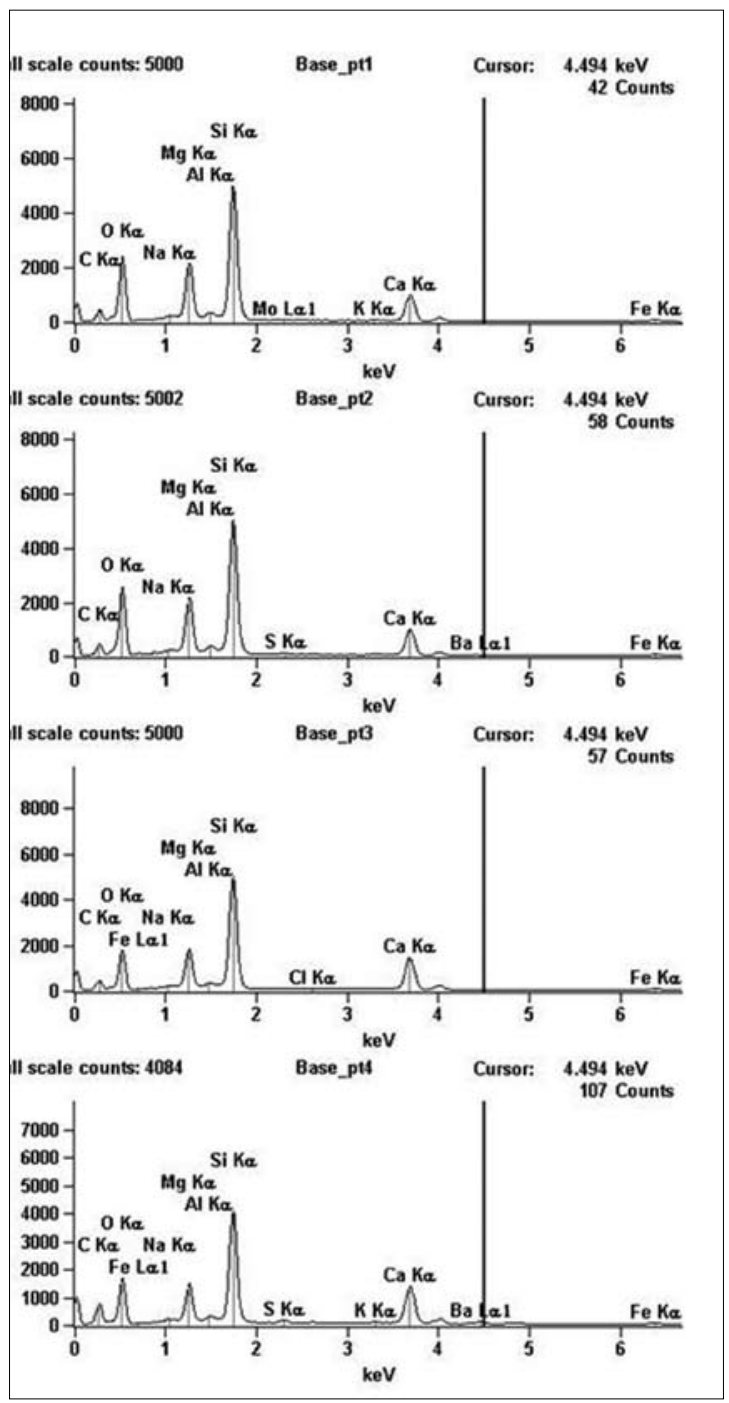

Figura A-3 - Espectros EDS coletados nos pontos 1, 2, 3 e 4 respectivamente, mostrados na Figura $A-2$
Base

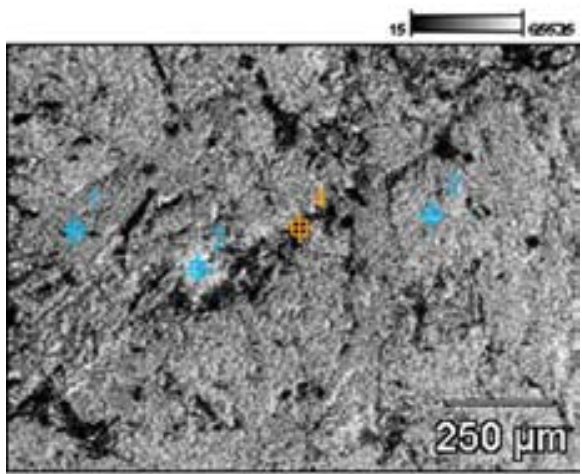

Figura A-2 - Imagem BSE da amostra de Piroxênio, voltagem de aceler ação de 17,0 kV e magnificação de 100 x. Sobre a imagem estão marcados os pontos 1, 2, 3 e 4 que foram alvos da análise com EDS

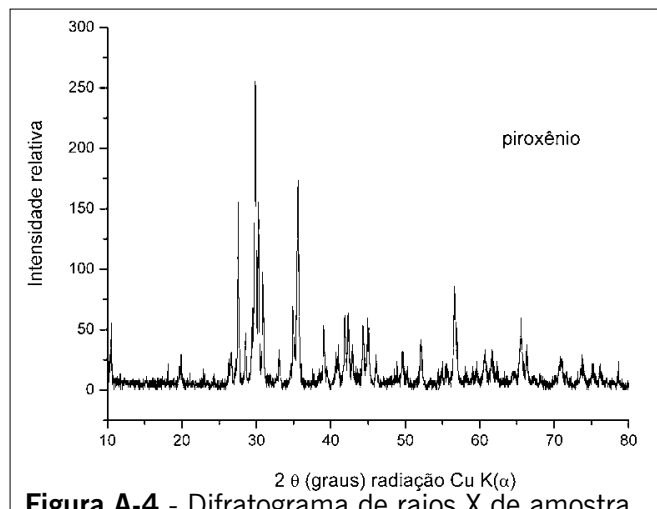

Figura A-4 - Difratograma de raios $X$ de amostra de Piroxênio

(a)

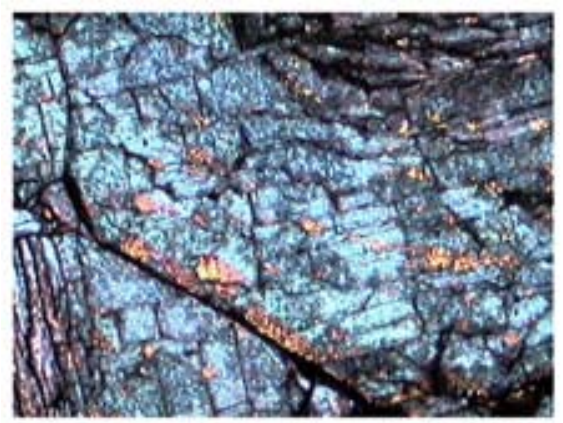

(b)

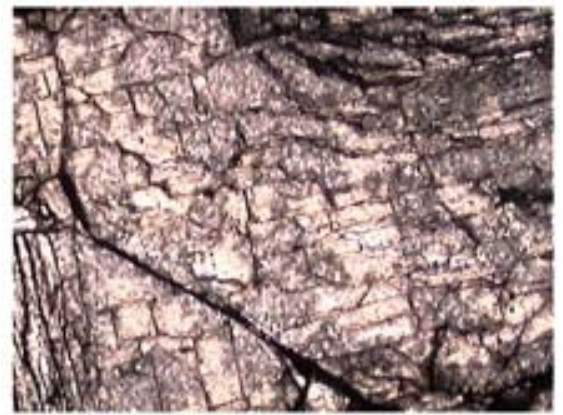

Figura A-5 - Fotomicrografias de Piroxênio: (a) /uz natural e (b) luz polarizada 


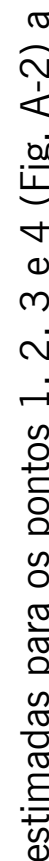

है

임

$\overline{\mathrm{O}}$

$\frac{E}{\alpha}$

○

(1)

芯 \}

$\stackrel{\mathbb{E}}{E}$

$\frac{\varepsilon}{\Phi}$

ㅇำ

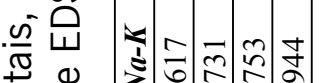

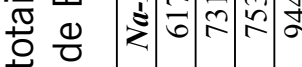

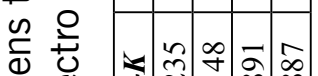

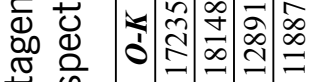

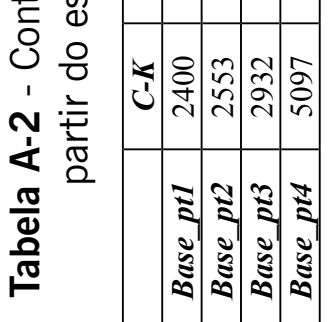

$\stackrel{\sim}{\sim} \quad \frac{\infty}{\sim}$

窇

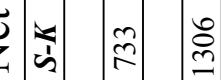

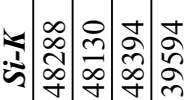

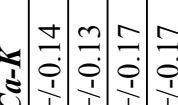

క

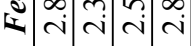

$\longleftarrow$ ป

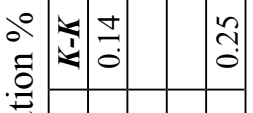

苞

оี

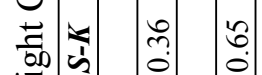

ए

$\div$ เุ

$\dot{n}=20$

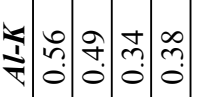

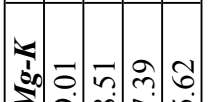

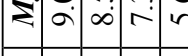

¿̇

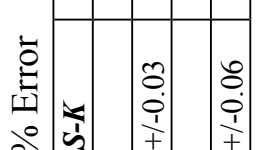

행

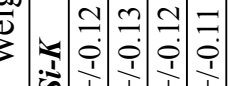

$=\infty$

ठิ

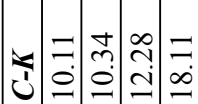

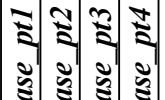

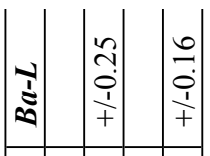

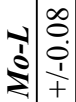

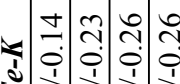

造 $\frac{1}{+} \frac{1}{+} \frac{1}{+} \frac{1}{+}$

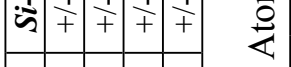

$=12$

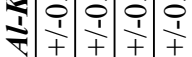

$=$ 의 응ㅇํ.

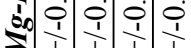

$\nsucc \stackrel{0}{\circ}: \infty$

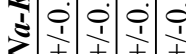

ㄴ.?

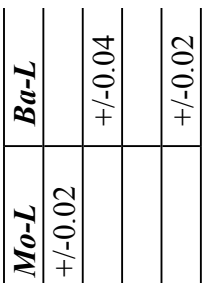

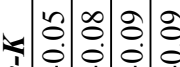

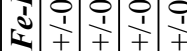

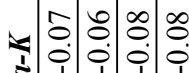

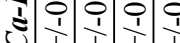

క1

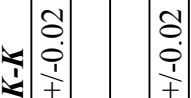

కิ ปิ $\cong \infty$

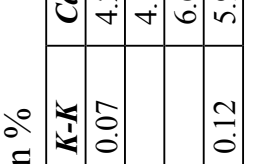

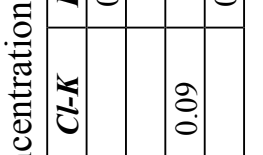

$\frac{1}{3}$

주․

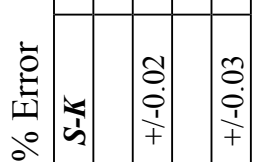

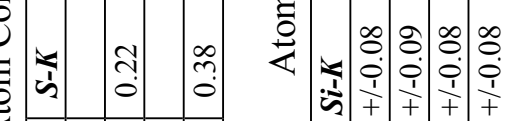

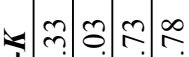

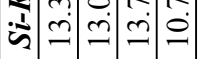

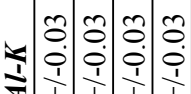

ฟ

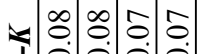

然

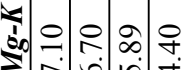

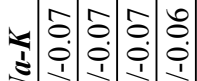

ปี

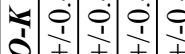

$=$ ฯ

ปิ

กิ กิ ?ి के

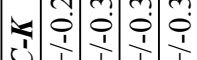

$=า \infty . \infty$

ป

$จ ะ$

$จ ะ$

जิ
ถิ ?ำ ㄴำ

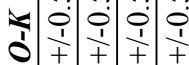

กำ กิ

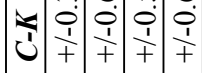

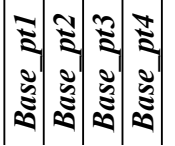




\section{Questões}

Questão A-1) É convenção, na Geologia, apresentar a tabela dos teores de elementos, na forma de óxidos, na ordem decrescente do estado de oxidação. Organize a Tabela A-1 segundo esta convenção.

Questão A-2) Calcule a fórmula estrutural nos quatro pontos analisados por EDS, na base de 6 oxigênios, conforme Anexo 1, de Deer et al. (2000), projete os resultados no diagrama de Morimoto (1988, apud Deer et al. 2000) e classifique o tipo de Piroxênio.

Questão A-3) Proceda da mesma maneira com o resultado obtido por FRX e compare o ponto projetado no diagrama de Morimoto (1988) a partir desta técnica, com os pontos obtidos no EDS.

Questão A-4) Faça o recálculo da análise da amostra. O recálculo da fórmula deverá ser feito após a identificação das fases minerais presentes e deve envolver uma estimativa dos teores relativos de cada fase, se houver mais de uma.

Questão A-5) Identifique a fase escura e a fase cinza.

Questão A-6) Compare a \% em massa obtida por EDS com àquela obtida por FRX levando-se em consideração que a análise do EDS é pontual e a do FRX é uma média obtida de uma massa representativa de toda a amostra.

Questão A-7) Interprete o difratograma de raios $\mathrm{X}$ comparando as posições dos picos medidos com as dos picos das fases minerais de referência que você supõe estarem presentes. Os difratogramas das fases dos minerais de referência podem ser visualizados no site mincryst.

\section{Avaliação da atividade didática proposta}

A atividade didática desenvolvida pelos alunos foi avaliada no final do semestre por meio de um questionário contendo 13 questões relativas ao trabalho realizado. Os formulários foram preenchidos anonimamente ao final da última prova do semestre e colocados em um envelope que foi lacrado em sala de aula e só foi aberto após a emissão oficial das notas finais da disciplina.

Os resultados obtidos nesta avaliação podem ser vistos na tabela 2 .

O questionário foi dividido em três grupos de perguntas, o primeiro grupo corresponde a oito perguntas $(1 \mathrm{a} 8)$ relativas à natureza e ao desenvolvimento do trabalho realizado. O segundo grupo corresponde a três perguntas ( 9 a 11) relativas ao uso do computador e da internet e o terceiro grupo corresponde a duas perguntas (12 e 13) relativas à opinião dos alunos sobre as técnicas estudadas.

Foram atribuídos pesos diferentes a cada uma das quatro respostas dadas às perguntas dos grupos 1 e 2 . Para a resposta A, a mais positiva, foi dado o peso 2, à resposta $\mathrm{B}$ foi dado peso 1 , à resposta $\mathrm{C}$ foi dado peso -1 e à resposta $\mathrm{D}$, a mais negativa, foi dado peso -2 .

Uma análise geral dos resultados obtidos mostra que os alunos consideraram a atividade realizada positiva em todos os aspectos. Como também, foi considerada igualmente positiva a contribuição da atividade para o entendimento da utilização das técnicas em Geologia e as discussões durante as apresentações que foram úteis, complementando este entendimento, o que possibilitou à maioria dos alunos a compreender a utilização das técnicas estudadas em sua atividade profissional. A atividade desenvolvida possibilitou aos alunos articular o conhecimento teórico sobre as propriedades dos elementos presentes em minerais e rochas com um problema prático, identificar amostras de minerais e rochas reais a partir de dados provenientes de análises instrumentais, uma situação concreta que demandará a sua futura prática profissional. Segundo Marx e Engels "o homem só conhece aquilo que é objeto de sua atividade, e conhece porque atua praticamente". A práxis, portanto, é compreendida como atividade material, transformadora e orientada para a consecução de finalidades.

O trabalho realizado pelos alunos permite compreender dialeticamente, o conceito de práxis, que relaciona a teoria e a ação. Sobre esta forma de compreender, Vázquez (1977), mostra que "uma teoria é prática na medida em que materializa, por meio de uma série de mediações, o que antes só existia idealmente como conhecimento da realidade ou antecipação ideal de sua transformação".

E, a partir desta diferenciação, compreender a especificidade do trabalho educativo escolar para que se possa verificar a possibilidade de desenvolver profissionais competentes a partir da universidade.

Dentre as perguntas do grupo 1 , as que tiveram a avaliação mais negativa foram as questões 3 e 7 . A interpretação que damos sobre esta avaliação na questão 3 , é que os alunos acreditam que a dificuldade na interpretação dos dados esteja relacionada com o fato de não terem manipulado as amostras, utilizado os equipamentos e coletado os dados, de- 


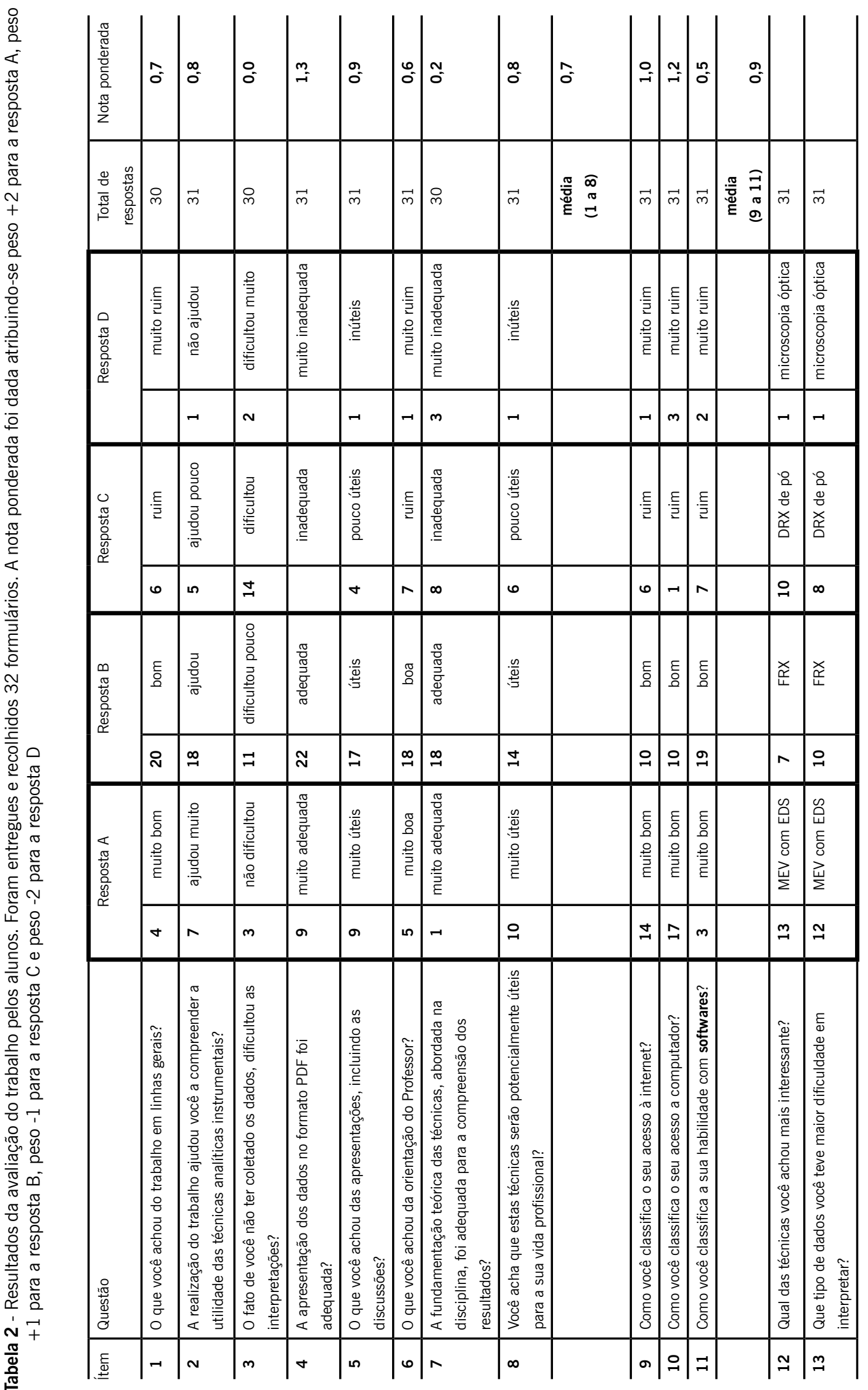


monstrando que grande parte deles apresentam uma visão empirista-indutivista do conhecimento científico (Borges,1996), ou seja, acreditam que por meio da prática (observação, coleta de dados e operando equipamentos) conseguirão compreender melhor a teoria (fundamentação das técnicas), desconhecendo que a forma como é planejada e desenvolvida uma atividade prática provém da reflexão que se tem da teoria.

Em relação à questão 7, relativa ao fato da fundamentação teórica ter sido suficiente para embasar as interpretações, embora apresente uma média positiva, uma análise mais minuciosa das apresentações e depoimentos dos alunos durante a exposição dos seus trabalhos nos fez refletir sobre a inadequação da atividade para a disciplina de Química Inorgânica e Experimental, pois a abordagem teórica das técnicas instrumentais não sendo aprofundada nesta disciplina dificulta a interpretação dos dados para algumas amostras de minerais e rochas mais complexas e sem um mínimo de conteúdo teórico o movimento dialético que estabelece a práxis não se concretiza. Desta maneira os professores acreditam que a proposta didática aqui apresentada deve fazer parte da parte experimental da disciplina Mineralogia Descritiva para atender os objetivos iniciais pensados para a atividade.

Quanto às respostas dadas às perguntas do grupo 2 a que teve avaliação mais positiva foi a questão 10 relativa ao acesso a computador. A avaliação mais negativa ficou por conta da habilidade pessoal com softwares, pergunta 11. Na avaliação dos professores as planilhas de cálculos para manipular resultados é o software menos dominado pelos alunos. Definir quais softwares são os mais limitantes deve ser objeto de estudos futuros na área de ensino, principalmente aqueles demandados para atuação dos geólogos no campo profissional. As médias ponderadas, calculadas para os dois grupos de perguntas, revelam que as habilidades com computador e acesso à internet (média 0,9) foram menos limitantes que o desenvolvimento do trabalho propriamente dito (média 0,7 ).

No terceiro grupo de perguntas nos surpreende o fato de apenas um aluno ter achado como técnica mais interessante a microscopia ótica tendo em vista que esta técnica é informativa e muito atrativa visualmente. As técnicas classificadas como mais interessantes foram MEV e DRX e as que apresentaram mais dificuldade de interpretar foram MEV e FRX. Apesar de não ter sido separado, no formulário, a MEV (micrografias) de EDS (análise elementar percentual em um dado ponto da micrografia) os professores acreditam que a dificuldade a que se referem os alunos em relação ao
MEV foi, na verdade, atribuída ao EDS que, em essência, apresenta a mesma dificuldade de interpretação do FRX (análise elementar percentual média do mineral). Sendo assim, a maior dificuldade de interpretação terá sido em relação aos resultados numéricos, caso do FRX e EDS, e não dos resultados qualitativos, caso das micrografias MEV, dos espectros DRX e das imagens de microscopia ótica.

A qualidade dos trabalhos realizados pelos alunos foi muito variada, houve alunos que interpretaram com facilidade os resultados, superaram obstáculos com grande habilidade em relação ao domínio da fundamentação teórica, buscando na literatura subsídios para auxiliá-los nas interpretações e durante as apresentações de outras equipes propuseram soluções com grande relevância para resolver os problemas de interpretação. Por outro lado houve alunos que não se interessaram pelo trabalho, lidando com indiferença e desinteresse. Esta postura observada por alguns alunos se deve a sua formação ao longo de toda sua vida escolar pelo contato com uma metodologia de ensino tradicional, onde o ensino-aprendizagem é centrado no professor que expõe todo o conteúdo, explica os conceitos na sua forma final, fornece respostas definitivas, diz aos alunos se eles estão certos ou errados e explica passo a passo a solução do problema a partir de um único procedimento, quando deveria elaborar questões investigativas para extrair os conceitos, extrair dos alunos respostas para revelar o que eles conhecem ou pensam sobre o conceito, fornecer aos alunos oportunidade para procurar resoluções para o problema proposto, propiciar uma discussão do problema e incentivar os alunos a explicarem os conceitos com as suas próprias idéias (Ferreira 2006).

Assim como houve uma grande diferença nas atitudes e interesses pessoais dos alunos pelo trabalho, também houve variações no grau de dificuldade na interpretação de dados pelas equipes. Há minerais como o quartzo em que a interpretação dos dados apresentada é muito simples, enquanto que os dados para a amostra de Piroxênio são bem difíceis, o que dificultou a avaliação por parte dos professores. Esta disparidade no grau de dificuldade entre os trabalhos não desqualifica a atividade proposta, mas deverá ser considerada pelo professor numa próxima aplicação.

A avaliação das dificuldades dos alunos em relação à interpretação das técnicas aponta para o reforço teórico na interpretação dos dados de análises elementares percentuais (recálculos) e DRX e para uma maior valorização da utilidade da microscopia ótica com luz polarizada em Geologia. 


\section{Considerações Finais}

As novas demandas impostas pela globalização da economia e pela reestruturação produtiva exigem que a educação proponha um novo princípio educativo e uma nova proposta pedagógica que formem um profissional apto a conviver neste novo mundo do trabalho.

O profissional de Geologia de nível superior precisa estar preparado para enfrentar o mundo do trabalho cada vez mais competitivo e exigente, como também, preparado para enfrentar os desafios de uma nova sociedade que apresenta novas modalidades de emprego e novas configurações de trabalho. Os cinco anos de graduação devem servir para, além da aquisição dos conhecimentos necessários à formação desse profissional, desenvolver atitudes maduras e buscar alicerçar uma postura profissional diferenciada.

Consideramos que a atividade didática proposta permite atender mesmo que parcialmente às competências exigidas para formação do geólogo, que hoje passam pelo pensar, pelo ler a realidade, compreender os processos, identificar problemas e gerar soluções o que requer competências cognitivas complexas que implicam o desenvolvimento da inteligência, muito além da memória, exigindo uma articulação entre o fazer e o conhecer.

\section{Agradecimentos}

Os autores agradecem às seguintes pessoas pela colaboração na realização do presente trabalho:

No Centro de Microscopia Eletrônica - UFPR: Vera Regina Fontana Piontek, Sérgio Tokunaga, Rosângela Borges Freitas e Prof. Dr. Ney Mattoso.

No Laboratório de Análise de Minerais e Rochas - LAMIR UFPR: Rodrigo Secchi, Douglas Piovesan, Luciane Lemos do Prado, Elisiane Roper Pescini, Carlos Lara Ribeiro, Joaniel Munhoz Martins.

No Departamento de Química da UFPR: Prof. Dr. Aldo Zarbin, Prof. Dr. Fernando Wypych, Paula Zangaro e Mariane Schnitzler.

\section{Referências Bibliográficas}

Afonso J.C., Aguiar R.M., Gomes L.M.B. 2004. Análise química de sais de cobre fabricados entre 1877 e 1995, Quim. Nova, 27(4): 678-683.

Antunes R.L.C. 2000. Adeus ao Trabalho? : Ensaio sobre as metamorfoses e a centralidade do mundo do trabalho. $7^{\mathrm{a}}$. ed. ampl., São Paulo: Cortez.

Assis J.F.P., Lazzarotto A. 2006. Relato Final do V Encontro do Fórum Nacional de Cursos de Geologia. Cuiabá, junho de 2005. Terree Didatica, 2(1):91-104. http://www.ige.unicamp.br/terraedidatica/ $>$.

Borges R.M.R. 1996. Em Debate: Cientificidade e Educação em Ciências. Porto Alegre: SE/CECIRS. p. 58-60.

Carneiro C.D.R. 2005. Relato Final do I Encontro do Fórum Nacional de Cursos de Geologia. João Pessoa, set. 2002. Terre Didatica, 1(1):70-73. http:// www.ige.unicamp.br/terraedidatica/

Carneiro C.D.R., Assis J.F.P. 2005. Relato Final do II Encontro do Fórum Nacional de Cursos de Geologia. Belém, maio 2003. Terre Didatica, 1(1):74-83. http://www.ige.unicamp.br/terraedidatica/

Carneiro, C.D.R.; Nummer, A.R.; Assis, J.F.P.; Pinho, F.E.C. 2005. Relato Final do III Encontro do Fórum Nacional de Cursos de Geologia. Diamantina, junho de 2004. Terre Didatica, 1(1):84-96. http://www.ige.unicamp.br/terraedidatica/

Deer W.A., Howie R.A., Zussman J. 2000. Minerais constituintes das rochas. Uma introdução. Lisboa: Fundação Calouste Gulbenkian.

Ferreira L.H., Hartwig D.R. 2006. Grupo de Trabalho 2. Experimentação. In: I Encontro Paulista de Pesquisa em Ensino de Química, Universidade de Campinas - Instituto de Química. URL: http://gpquae.iqm.unicamp.br/EPPEQ.pdf. Publ. Abril 2006.

Gill R. 1989. Chemical Fundamentals of Geology. 2 ed. London: Kluwer.

Gomes C.B. 1984. Técnicas Analíticas Instrumentais Aplicadas à Geologia. São Paulo: Edgard BlücherPró-Minério.

Harris D. 2002. Quantitative Chemical Analysis. 6 ed. New York: W.H. Freeman Publ.

Klein C., Hurlbut A.S.Jr., after J.D. Dana 1999. Manual of Mineralogy. $21 \mathrm{ed}$. New York: Wiley.

Krauskopf K.B. 1979. Introduction to Geochemistry. 2 ed. New York: Wiley.

Kuenzer A.Z. 2001. Ensino de $2^{\circ}$ Grau, o trabalho como princípio educativo. 4 ed., São Paulo: Cortez, $166 \mathrm{p}$.

Kuenzer A.Z. 2003. Conhecimento e Competência no Trabalho e na Escola, Educação \& Linguagem, 8:45-68.

Marx K., Engels F. 1998. A ideologia alemã. Trad. Anto- 
nio de Pádua Danesi. São Paulo: Martins Fontes.

Mincryst http://database.iem.ac.ru/mincryst/index. php

Nummer A.R., Godoy A.M.; Lazzarotto A., Carneiro C.D.R., Schultz C.L., Tubbs Filho D., Guimarães E.M., Althoff F., Assis J.F.P., Pinho F.E.C., Sobreira F., Carvalho I.S., Sabadia J.A.B., Fernandes Filho L.A., Toledo M.C.M.de, Fernandes M.L.S., Costa R.D.da, Machado R., Menegat R., Nadalin R.J., Santos R.A.A.dos, Vasconcelos S.M.S., Marques T.M., Souza Z.S.de. 2005. Diretrizes Curriculares para os Cursos de Graduação em Geologia e Engenharia Ge- ológica. Terre Didatica, 1(1):64-69. < http://www.ige. unicamp.br/terraedidatica/v1n1/t_didatica_2005 v01n01_p064-069_nummer_et_al.pdf>.

Reed J.B. 2005. Electron Microprobe Analysis and Scanning Electron Microscopy in Geology. 2 ed. Cambridge: Cambridge Univ. Press.

Skoog D.A., Holler F.J., Nieman T.A. 1998. Principles of Instrumental Analysis. 5 ed. Philadelphia: Harcourt Brace.

Vasquez A.S. 1977. Filosofia da Práxis. Trad. Luiz Fernando Cardoso. 2 ed. Rio de Janeiro: Paz e Terra.

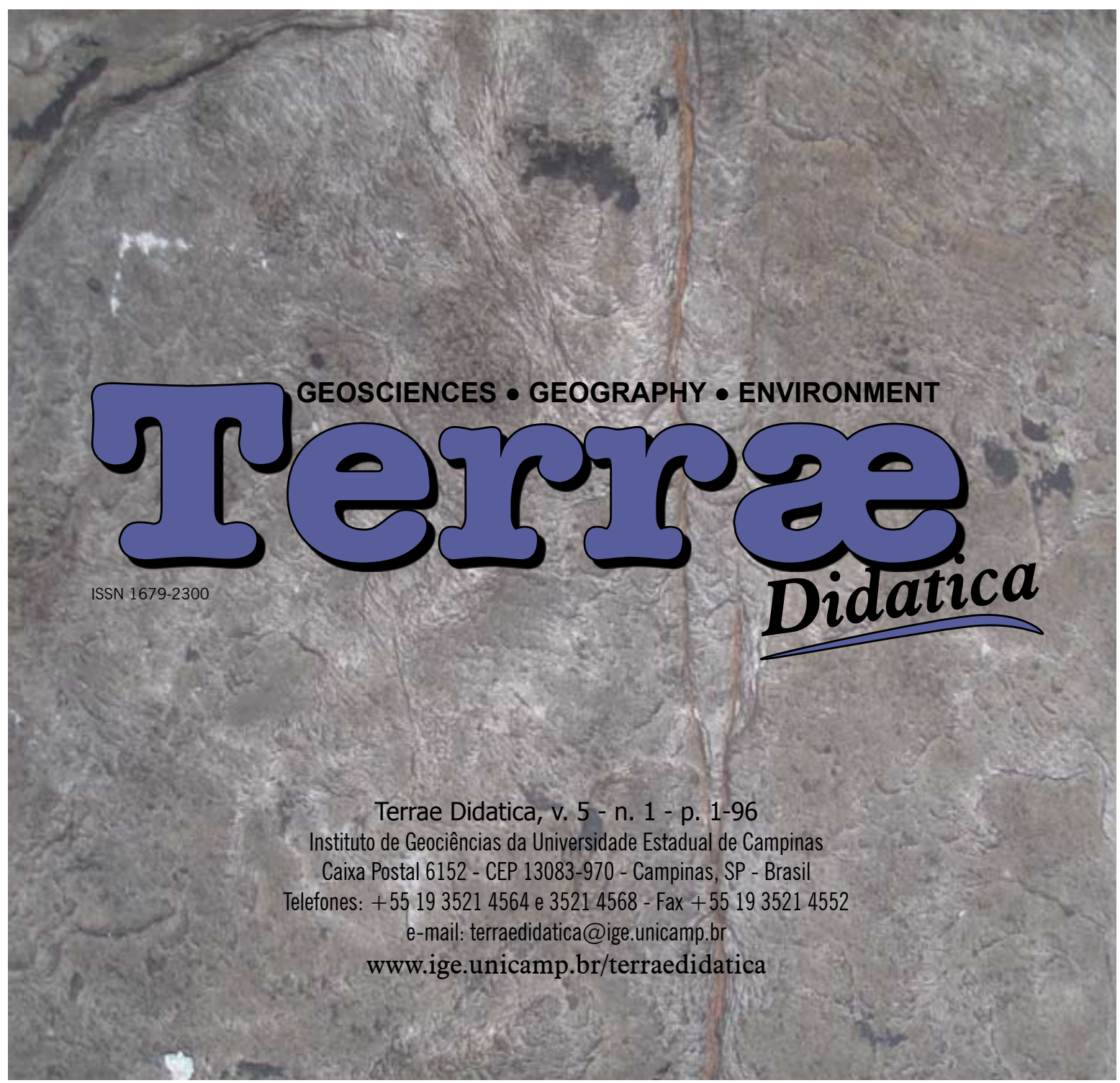

